\title{
El Pawkar Raymi como afirmación de la identidad étnica en la migración: el caso de los migrantes kichwa-otavalo en Santiago de Chile
}

\section{Pawkar Raymi, an affirmation of the ethnic identity in migration: case of kichwa-otavalo immigrants in Santiago de Chile}

Cecilia Bravo Muñoz ${ }^{1 D}$ https://orcid.org/0000-0003-2742-7277

Jorge Iván Vergara del Solar ${ }^{2}$ (D) https://orcid.org/0000-0002-3639-8562

Angélica Ordóñez Charpentier ${ }^{3}$ (D) https://orcid.org/0000-0003-4731-4114

${ }^{1}$ Universidad Central del Ecuador, Quito, ECUADOR. Email: jcbravom@uce.edu.ec.

${ }^{2}$ Universidad de Concepción, Concepción, CHILE. Email: jorgeivergara@udec.cl

${ }^{3}$ Universidad Andina Simón Bolívar, Quito, ECUADOR. Email: angelica.ordonez@uasb.edu.ec

\section{Resumen}

Este trabajo establece un análisis teórico y empírico en torno a las significaciones que se desarrollan en la festividad del Pawkar Raymi, de los indígenas migrantes kichwa-otavalo en la ciudad de Santiago de Chile. Se marca así una ruptura con la cotidianidad para dar paso a actividades festivas, lúdicas y de interacción en las que se establecen procesos de reinterpretación de la identidad étnica y el sentido de pertenencia a la comunidad, delineando problemáticas que muchas veces no se hacen evidentes en la comunidad de origen porque responden a nuevos elementos de la sociedad globalizada. El enfoque parte de un análisis conceptual antropológico y de la psicología social, desde los testimonios obtenidos, y se trabaja con fuentes de primera mano para entender los procesos de afirmación de la identidad étnica kichwa-otavalo.

Palabras clave: comunidad, pertenencia, tradición, capital social, capital cultural.

\begin{abstract}
This paper establishes a theoretical and empirical analysis about the meanings that are developed in the "Pawkar Raymi", a festivity of the migrating indigenous kichwa-otavalo in the city of Santiago de Chile. A rupture within the everydayness can be seen, allowing festive, ludic and interactive processes to occur, where processes of ethnic identity reinterpretation and sense of belonging to a community occur; outlining issues that most of the time are not evident within the community of origin because they respond to new elements in a globalised society. The approach comes from an anthropological conceptual analysis and from social psychology, from the testimonies obtained, working with first hand sources in order to understand the processes of ethnic identity affirmation of the kichwa-otavalo.
\end{abstract}

Keywords: community, sense of belonging, tradition, social capital, cultural capital.

Recibido: 18 mayo 2019. Aceptado: 10 septiembre 2019 


\section{Introducción}

El presente trabajo de investigación pretende establecer un análisis teórico, con un enfoque etnográfico, de la celebración del Pawkar Raymi en el contexto de la migración kichwa-otavalo en la ciudad de Santiago de Chile. Los kichwa-otavalo celebran el Pawkar Raymi en la época en que se conmemora el florecimiento, coincidente con el carnaval, pero además "marca un proceso en el calendario agrícola del maíz, planta emblemática (junto con el chocho) de la sierra andina ecuatoriana, y que florece en febrero" (Ordóńez, 2008, p. 82). A diferencia de Ecuador, en el contexto de la migración en Santiago de Chile, esta fiesta se lleva a cabo durante la primera semana de enero, acomodándose a las necesidades laborales de los migrantes kichwaotavalo, quienes se movilizan a lo largo de las costas de Chile y hacia otros sitios turísticos de veraneo para comerciar los productos de temporada.

Este artículo tiene como objetivo interpretar los elementos subjetivos de la identidad étnica, y los elementos culturales que se manifiestan en el Pawkar Raymi en el proceso migratorio. Se enmarca en la teoría del capital social y cultural de Pierre Bourdieu (2000) y en la teoría de la invención de la tradición de Hobsbawm (2002), por lo que se ha generado un análisis contextualizado en la ciudad de Santiago de Chile, en la interacción simbólica de la fiesta y en la comprensión de los nuevos significados que se establecen en la comunidad migrante kichwaotavalo en esta ciudad.

Se constata que la fiesta se constituye en un punto de encuentro, cuyo objetivo fundamental es la integración de la comunidad kichwa-otavalo y el reforzamiento de su sentido de pertenencia, de identidad nacional y étnica, de ruptura contrahegemónica de su situación migrante y de generar capitales sociales y simbólicos en torno a la interacción con otros miembros de la comunidad.

La base empírica se construyó a partir de la observación participante durante la semana de celebración del Pawkar Raymi en la ciudad de Santiago, del 2 al 6 de enero del 2018. Durante los seis meses posteriores se realizaron 11 entrevistas semiestructuradas, en profundidad, principalmente a las personas involucradas en la organización del evento 2018, así como de los años anteriores. También, se entrevistó a diferentes kichwa-otavalo en condición de migrantes en Chile, recurriendo a visitas de campo en los mercados y las calles, en Santiago y otras ciudades de Chile, donde se asientan los comerciantes a ofrecer sus productos. A continuación en la Tabla 1 se presentan los datos de los informantes cuyos testimonios han sido citados: 
Tabla 1. Informantes

\begin{tabular}{|c|c|c|c|}
\hline N. & Nombres & Edad & Sexo \\
\hline 1 & Walter & 62 años & Masculino \\
\hline 2 & Anderson & 30 años & Masculino \\
\hline 3 & Camilo & 43 años & Masculino \\
\hline 4 & Sergio & 35 años & Masculino \\
\hline 5 & Jacinto & 22 años & Masculino \\
\hline 6 & Darwin & 18 años & Masculino \\
\hline 7 & Charly & 19 años & Masculino \\
\hline 8 & Ángel & 33 años & Masculino \\
\hline 9 & María & 45 años & Femenino \\
\hline 10 & Adriana & 37 años & Femenino \\
\hline 11 & Juan & 42 años & Masculino \\
\hline
\end{tabular}

Fuente: Elaborada por Bravo, Vergara y Ordóñez.

Algunas entrevistas se realizaron in situ, al igual que la observación participante, la cual se encuentra esquematizada y estructurada en la respectiva guía de observación del evento. El proceso de inserción en el campo también fue planificado mediante la elaboración de una guía semiestructurada para las entrevistas. Ambas técnicas permitieron obtener una gran cantidad de información, la misma que fue procesada y codificada utilizando el programa de análisis cualitativo Atlas Ti, junto con la interpretación de los miembros del equipo de investigadores a partir de procesos de diálogo y retroalimentación.

Con estas metodologías se accedió a las significaciones, experiencias, recuerdos y análisis en torno al Pawkar Raymi, sobre la base de un trabajo de campo. En él se estableció un reconocimiento cultural y referencial por redes, en las que los participantes iniciales reportaron a otros conocidos que podían aportar mayor información, incluyendo aquellos migrantes que tenían o tuvieron contacto con la celebración en Peguche, Ecuador, tomando en cuenta que "la tradición oral puede ser muy precisa, transmitiendo una sustancia cultural relativamente continua, aunque rearticulada, durante varias generaciones" (Clifford, 1999, p. 62). Se constituyó así, a partir de las entrevistas, una conexión desde el diálogo que busca construir nuevos sentidos en torno a la identidad, simbología, pertenencia, cultura, tradición, pero ante todo en la comprensión de lo humano en situación de movilidad, que genera espacios de encuentro con los otros.

\section{El Pawkar Raymi y la tradición migratoria de los kichwa-otavalo}

Los Raymi (fiesta o ceremonia ritual) en el mundo indígena kichwa-otavalo constituyen una actividad fundamental de la comunidad y de la familia, en la que confluyen una serie de aspectos simbólicos y vitales heredados desde épocas antiguas y que actualmente se fortalecen como herramientas identitarias. En esta actividad existe una participación activa de los sujetos como portadores y transmisores de los valores culturales. "De ahí que el carácter tradicional abarque 
la totalidad de las relaciones sociales a través de la transmisión generacional en un tiempo y espacio que configuran el sentido de vida de un pueblo" (Escudero, 2017, p. 29).

Este espacio festivo genera un simbolismo de interacción entre los individuos, la comunidad y el mundo, en el que existe una clara conexión con los ciclos lunares y solares, estableciendo una significación entre la fertilidad humana y de la Pachamama que entrega los alimentos; de ahí que la ritualidad de la fiesta, antes que una súplica, se constituye principalmente en una manifestación de agradecimiento.

En el mundo indígena andino se celebran cuatro fiestas rituales ligadas al período agrícola, tomando en cuenta los ciclos vitales y la identidad simbólica que se genera a partir de los solsticios y equinoccios en los que se agradece a la tierra por la vida. Cronológicamente, se inicia con el Pawkar Raymi en los meses de febrero y marzo, cuando se conmemora el retorno y el florecimiento; en junio, en el Inti Raymi, se celebra el tiempo de cosecha y agradecimiento a la Pachamama; el 21 de septiembre, en el equinoccio, el Koya Raymi corresponde al culto a la feminidad e inicio de un nuevo ciclo agrícola y el 21 de diciembre, en el solsticio, se celebra el Kapak Raymi.

Así, la fiesta permite -entre los participantes, miembros de la comunidad y forasteros- circular una intensa carga simbólica, un agradecimiento en torno a los ciclos vitales instaurando un espíritu especial de emotividad compartida, en la que se exalta la imagen de un "nosotros" y se reafirman los lazos de integración social (Escobar, 2009, p. 11). Es importante tomar en cuenta que la festividad ritual supone una puesta en escena de lo social, en la cual interactúan una serie de significados que permiten visibilizar el acto de agradecimiento, espiritualidad y cercanía de la comunidad con la tierra que la alimenta, rompiendo con la tensión acumulada en la cotidianidad del trabajo y abriendo un nuevo espacio de entrega a lo festivo, "permitiendo que los celebrantes soporten la rutina a la que deben regresar en cuanto acaban los festejos" (Díaz Polanco, 2009, p. 26).

Los indígenas otavalo son una comunidad en constante movilidad migratoria, al punto que se ha instituido en un modo de vida y en una caracterización propia de su identidad el movilizarse por diversas regiones del mundo, insertándose en el mercado internacional por medio de "la comercialización de productos 'étnicos': artesanías, música folclórica y el turismo" (Torres, 2005, p. 435), con lo cual se establece un modelo de desarrollo y crecimiento comunitario en el que la migración se constituye en la base para el adelanto socioeconómico. De ahí que la ciudad de Otavalo y alrededores sostenga altos índices de movilidad social, pero también de inversión económica por las remesas de los comerciantes que recorren el mundo, lo que obliga a "recomponer y readecuar los pilares tradicionales de la comunidad (como los sistemas de cargo tradicionales), al tiempo que la estructura comunitaria se apoya ahora en nuevas pilastras, como es el caso de las remesas de sus migrantes" (Díaz Polanco, 2009, p. 8).

La migración interna y transnacional transformó las relaciones en la comunidad de Otavalo a un ritmo vertiginoso, no solo dentro del colectivo étnico sino en las relaciones con el Estadonación. Un ejemplo de ello es la ciudad de Otavalo que, décadas atrás, era completamente mestiza y en la que los indígenas no podían entrar a vender sus productos; pero pasó a ser habitada mayoritariamente por la población indígena, muchos de ellos dueños de inmuebles y empresas, quienes hasta la actualidad mantienen el control sobre la producción artesanal y su exportación. De esta forma, se establece un modelo de hegemónico, basado en la producción de riqueza, desde lo transnacional a la reinvención de las élites en la comunidad. 
El otavaleño ${ }^{1}$ reafirma su identidad en relación a elementos como el uso del idioma, la vestimenta, las tradiciones y costumbres propias del kichwa-otavalo. Sin embargo, aunque guarden diferencias socioculturales con espectro amplio de valores y costumbres similares, al interior del grupo tanto del sector urbano como del rural, existen niveles socioeconómicos marcados y movilidad de clase que los identifica entre indios, pobres y ricos (Sarabino, 2007, p. 39).

Estos procesos de movilidad no inciden solo en la economía de la ciudad y el comercio de las comunidades, sino que establecen una serie de redefiniciones de la identidad en torno a procesos relacionales entre los migrantes y las comunidades que los acogen. Un proceso de reivindicación de la identidad en la que, desde sus propias estructuras étnicas, busca establecerse como principios o tradiciones que los acompañan dentro de desarrollos de construcción en los diversos destinos que los reciben. Esta construcción de la identidad se da siempre en relación con un "otro", en una estrecha interacción simbólica, de patrones y significados culturales, pues es un proceso en el que intervienen lo cultural, lo material y lo social (Larraín, 2003).

En este contexto, Chile -como país de acogida- en los últimos años ha experimentado un gran crecimiento del flujo migratorio desde los países vecinos y de Latinoamérica en general, sin embargo, carece de una política migratoria regulada desde un enfoque de derechos (Jensen, 2009). Por lo que, un problema adicional para los kichwa-otavalo es que conviven en una sociedad cuyas representaciones culturales hacia los migrantes se expresan generalmente en un sentido de inferiorización, a veces cargado de estereotipos y prejuicios (Aravena y Silva, 2009) y que incuba manifestaciones de intolerancia y discriminación (Martínez, 2003), condiciones que, en las interacciones sociales desde la alteridad, se expresan en violencia simbólica (Aravena y Baeza, 2013). Esta situación afecta significativamente la identidad étnica, en muchos casos tiende a reforzarla; en otros, se opta por estrategias de adaptación a la cultura dominante.

Por otra parte, en la identidad étnica se presenta el sentido de pertenencia, sentimiento que vincula al individuo con el grupo al que adscribe por nacimiento y que se sustenta en "un conjunto de valores, acciones y símbolos que constituyen un campo de comunicación y de interacción entre los individuos de una misma colectividad y que, al mismo tiempo, actúan como factores de diferenciación respecto a otros grupos" (Comas d'Argemir y Pujadas Muñoz, 1991, p. 34).

En medio de estos procesos de globalización y migración surge la invención de una tradición, el "Pawkar Raymi", que trasciende lo local y es llevado por los migrantes para establecer en el extranjero redes de reencuentro comunitario y espacios simbólicos entre quienes comparten la misma situación, para reafirmar los sentidos de pertenencia e identidad del ser kichwaotavalo en la realidad del migrante. En el exterior, en los países de acogida, los migrantes buscan mantener los vínculos con la comunidad de origen; "procuran reconstruirla -en realidad reinventarla- ahora bajo condiciones diferentes, la más destacable de las cuales es su carácter 'desterritorializado"' (Díaz Polanco, 2009, p. 8).

El Pawkar Raymi se inició en la comunidad de Agato (Sarabino, 2007; Yapud, 2015; Ordóñez, 2017), en el reencuentro de las familias transnacionales y en la confluencia del campeonato

1 Sarabino se refiere al indígena kichwa-otavalo, pues el término otavaleño es un gentilicio de la ciudad de Otavalo y aplica tanto para indígenas como para mestizos. 
de fútbol y del ritual del Tumarina. ${ }^{2}$ Es una celebración que congrega una serie de encuentros simbólicos en la comunidad, sobre todo en Peguche, en su cascada, que no es solo un centro turístico, sino un espacio natural en el que se generan rituales de purificación y retorno.

Coincide con la fiesta católica del carnaval, pero se establece como una celebración diferente, propia, que busca afirmar la identidad y pertenencia a la comunidad indígena, aunque incorpora elementos culturales pertenecientes al mundo mestizo occidental, panindígenas, globales, etcétera. Así, se establece como una lucha contrahegemónica con el mundo mestizo que pretende, de cierto modo, apropiarse de las festividades de la comunidad desde los aparatos estatales al servicio del turismo, tomando ventaja de la creciente folclorización de dichas fiestas:

Celebrar la fiesta por sí misma puede considerarse como una estrategia de movilización de recursos que favorecen a los sectores turísticos y, lo que es más, permite la continuidad de los discursos y prácticas folclóricas, propias de las políticas indigenistas culturales de antaño y las lógicas multiculturalistas posmodernas, que toleran y aceptan la diversidad (Tuaza, 2017).

En esta recreación, el Pawkar Raymi se configura principalmente en torno a un campeonato de fútbol y, a la vez, por la celebración cultural tanto del florecimiento (Tumarina) como del carnaval mestizo. De este modo, el Tumarina se restituye como una práctica ritual de purificación con el agua y las flores, que hace hincapié en valores como "el respeto y reconocimiento a las personas mayores, las bendiciones emanadas hacia todos los miembros de una comunidad cada vez más dispersa y, sobre todo, el liderazgo de las mujeres en la vida comunitaria" (Ordóńez, 2017, p. 287).

Es importante tomar en cuenta que esta festividad no solo gira alrededor del campeonato de fútbol, sino que va hacia la construcción de una cosmovisión y del reforzamiento del sentido de pertenencia, en donde la festividad se estructura como un principio espiritual, propio de las comunidades indígenas en las que la fiesta es un punto de anclaje con la comunidad y la trascendencia:

Nuestras culturas andinas, desde tiempos ancestrales, han hecho de los rituales lugares de convergencia. En los rituales se ofrenda, se diviniza, se purifica, se acerca a los espíritus mayores y a los dioses, para recibir de ellos la luminosidad de las energías del cosmos y del resplandor de la espiritualidad (Estrada Nasder, 2007, p. 100).

Por su parte, el carnaval es una tradición que se celebra en todo el Ecuador con una gran variedad de expresiones culturales según las diferentes regiones y ciudades. Sobresalen cinco elementos principales: la comida, las coplas, la música, el baile y el juego con agua. Se acostumbra hacer desfiles, comparsas con máscaras, carros alegóricos y otras manifestaciones culturales como el juego con agua, huevos, harina, tinta, espuma de carnaval; por lo general entre familiares, vecinos y conocidos. Esta costumbre de jugar con agua es de disfrute popular, tan arraigado que se lo considera el alma misma del carnaval, que persiste en el Pawkar Raymi pues, para la mayoría de la comunidad, este evento es la fiesta de carnaval, a pesar de algunos intentos por erradicar esta tradición.

2 Ritual de purificación con flores y agua que se practica durante la época de carnaval y que estuvo a punto de desaparecer, siendo reincorporado alrededor de 1998 (Ordóńez, 2017). 
En Ecuador la fiesta del Pawkar Raymi tiene una duración de 10 días y obedece a un orden específico: se inicia la noche de vísperas con una misa, la banda del pueblo y los castillos de juegos pirotécnicos y concluye con el partido final del campeonato, el Miércoles de Ceniza. La inauguración oficial se realiza con un desfile de las autoridades, los organizadores, los equipos con sus madrinas y un grupo de hombres y mujeres que llevan los medianos, esto es, la comida que será ofrecida a los asistentes; también están la presencia del Coraza, el Loa y los Yumbos; posteriormente, el baile del fandango, la presentación de grupos musicales y baile general (Ordóñez, 2017).

El ritual del Tumarina y el Runa Kay son los eventos culturales primordiales del Pawkar Raymi. El Runa Kay y la elección de la Nusta están institucionalizados desde el 2004, y cuyas características están muy ligadas al orgullo de la identidad kichwa-otavalo, particularmente enfocado a la lengua, a la vestimenta como un "traje de gala" y a la música (Ordóńez, 2017, p. 273), pero sobre todo al reencuentro de los valores comunitarios que rompen con lo cotidiano y rescatan el principio de identidad kichwa-otavalo.

El Pawkar Raymi se originó como un campeonato de fútbol en la comunidad de Agato. Sin embargo, debido a la insatisfacción respecto a la organización de este campeonato, en 1995 se realizó en Peguche un nuevo campeonato llamado Mundial de fútbol Peguche Tío, al cual dos años después se incorporó el Tumarina y otras manifestaciones culturales que se conocieron desde entonces como la fiesta del Pawkar Raymi (Ordóńez, 2008).

Esta fiesta así establecida se posiciona como un proceso de ruptura con la tradición hegemónica que considera un acontecimiento turístico las fiestas de las comunidades andinas, sometidas a las lógicas del capitalismo. Se constituye en una lucha por reivindicar la identidad kichwaotavalo, que, en su necesidad de reclamar el proceso de construcción de la identidad cultural, genera un espacio no solo con la toma de la plaza, como en el Inti Raymi, sino que también se reivindica como una fiesta que ratifica el simbolismo de la lucha indígena y los ciclos agrícolas para sostener su propia cosmovisión. Así también, la revalorización de principios comunitarios hasta la construcción identitaria en las nuevas generaciones, sujetas a los cambios de la globalización. De ahí que sea necesaria la invención de tradiciones en cuanto prácticas de naturaleza simbólica o ritual, gobernadas por reglas cuyo propósito es inculcar determinados valores o normas de comportamiento por medio de la repetición sistemática, lo cual implica una referencia a un pasado imaginado (Hobsbawm y Ranger, 2002).

Las tradiciones inventadas vienen a llenar los vacíos sociales, consecuencia de los cambios históricos. Se producen en momentos en que una sociedad debilitada sufre una rápida transformación o bien se han destruido los modelos sociales para los cuales se habían creado las viejas tradiciones. También se manifiestan cuando esas viejas tradiciones y sus defensores, portadores y promulgadores institucionales, han desaparecido o han sido eliminados. De allí que es importante establecer un análisis conceptual en torno a los procesos de etnicidad "reconstruida frente

3 Coraza es un personaje principal, representa una dignidad del mundo espiritual, la abundancia, poder y sabiduría. Viste un traje blanco con muchos encajes, brillos y lentejuelas, lleva sobre la cabeza una prenda con un penacho de plumas y una cortina de mullos de chaquira y cuentas colgantes con piedras de fantasía, que conforman un velo espeso que impide verlo y a su vez, él no puede ver ni oír, por eso va acompañado de los yumbos que son quienes lo resguardan. Son personajes que representan ser guardines y guerreros del mundo espiritual, ritual, también visten un traje de fondo blanco muy colorido, con la cabeza cubierta con un pañuelo de seda y una careta y llevan en la mano una lanza larga. El loa es un personaje niño, que recitan las loas a las divinidades indígenas y de la religiosidad católica. 
a las nuevas situaciones sociohistóricas; la reinvención de la tradición por la que costumbres aparentemente seculares adquieren una contemporaneidad política o como a los hechos contemporáneos se los carga estratégicamente de ancestralidad, estrategia consciente de lucha social" (Guerrero, 2002, p. 121). Se entiende así cómo se ha generado una especie de inspiración en el Pawkar Raymi de Agato y las demás tradiciones que aparecerán en la realidad migratoria. De hecho, y aunque se establecen críticas en torno al cambio de la tradición, se mantienen principios identitarios claves, sobre todo en los sujetos nacidos en Agato y Peguche.

Con base en la teoría de Hobsbawm y Ranger (2002) acerca de la invención de la tradición, Ordóńez (2017) analiza la estructura y las significaciones del Pawkar Raymi, así como los cambios sociales e históricos que lo impulsaron. En primer lugar, hace referencia a los orígenes de la fiesta, la cual, aunque es de tipo comunitario, surge de la iniciativa de un grupo de jóvenes, parte de la élite de los kichwa-otavalo de Peguche, que tuvieron como propósito revalorizar la cultura. De este modo se constituyeron también en guardianes y "defensores" de la tradición, al punto de tener el control de su continuidad, interpretación, difusión y modificación. En este sentido, Hobsbawm (2002) hace alusión a los grupos que se autonominan "tradicionalistas", que se consideran como los depositarios de la continuidad histórica y, por tanto, defensores de la tradición inventada.

El ritual del Tumarina, incorporado como parte de la expresión cultural de lo femenino, es un ejemplo claro de la invención de la tradición. Walter, indígena migrante, relata que cuando él era niño, en Ecuador, su mamá, sus abuelas "cogían las flores de las matas, las rositas, eso cogían y ponían en una ollita o un baldecito, y eso han llamado el Pawkar Raymi" (Walter, 62 años). Este ritual, de raíces antiguas, con el agua y las flores como elementos simbólicos de purificación, descontinuado en la práctica histórica, aparece nuevamente incorporado por los "defensores" de la cultura y las tradiciones.

Sin embargo, al ser desconocido para la gran mayoría, resulta una imposición, al punto de prohibir y estigmatizar costumbres populares tan arraigadas como el juego del carnaval con agua, práctica que se ha intentado en vano sustituir por el Tumarina; constituyéndose en este punto en un "intento desesperado por construir comunidades en las nuevas condiciones globalizadas, que resultan precisamente de la destrucción de los anteriores tejidos comunitarios y que terminan siendo en verdad sus sustitutos en esta etapa de la sobremodernidad o la posmodernidad" (Díaz Polanco, 2009, p. 4). Al final, el ejercicio simbólico se constituye a partir de la revitalización de los motivos culturales que permiten establecer procesos de identidad, representación y pertenencia a la comunidad. Esto se hace evidente en el relato de Anderson, residente en Santiago:

\section{El Pawkar Raymi es como algo importante, todo el mundo se viste como debe ser un indigena, con pantalón blanco, sus alpargatas blancas, el poncho. Esa fiesta es única- mente para los que se visten asi, si no te vistes asi, no puedes ingresar [...] pero, como dicen en todas partes con la plata mueve el mono, no importa si estás con cabello corto, pagas y entras nomás, es asi ahora, con plata haces todo [...]. Antes si hacian respetar eso mucho, no podian ingresar si no tenían cabello largo, si no era típico otavaleño in- dígena, ahora ya nada, con tal que tú pagues ya estás adentro (Anderson, 30 años).}

Como se puede apreciar en este testimonio, la obligatoriedad del traje tradicional para el Runa Kay en la fiesta de clausura dependerá del criterio de los organizadores, haciendo hincapié en lo deportivo, cultural o comercial. En este sentido, la vestimenta es uno de los principales valores 
de la identidad étnica, aunque para la mayoría de los jóvenes, en especial para los varones, el uso de la vestimenta indígena queda relegado a ocasiones especiales como esta. Por lo que, en el Runa Kay, se acude a la obligatoriedad en miras de la resignificación de la vestimenta indígena desvalorizada por procesos de globalización o integración con otras culturas.

Los constantes y acelerados cambios sociales, producto de décadas de migración transnacional, dividieron y diferenciaron a la comunidad entre migrantes y no migrantes, con consecuencias de carácter familiar, social, económico y político, por lo que la fiesta -en un análisis ex post facto- se constituye en un espacio de reencuentro, intentando soslayar el conflicto latente entre los grupos (Ordóñez, 2017). En este sentido, en el Pawkar Raymi estas prácticas culturales son las elegidas por los líderes indígenas en el contexto de las propuestas indigenistas institucionalizadas a nivel nacional e internacional. De igual modo, la migración transnacional afectó a la organización y prácticas de la comunidad misma. La invención de las tradiciones estaría, pues, ligada a la necesidad de control del grado y la velocidad de la transformación de la comunidad de Peguche: "[L]as tradiciones inventadas actuarían como un eje que reorganiza una diáspora extensa y compleja, el surgimiento de nuevas costumbres, una sociedad yuxtapuesta y la reformulación de lazos comunitarios" (Ordóñez, 2017, p. 292).

Para los kichwa-otavalo en el mundo moderno, el protagonismo político del movimiento indígena y su participación en instancias gubernamentales precisan de los líderes comunitarios y de quienes conforman las élites intelectuales, económicas y políticas, para generar nuevos ordenamientos y sentidos simbólicos a una festividad, es decir, como una tradición que integre a las nuevas generaciones, para desarrollar principios pedagógicos, ontológicos y epistémicos, contrahegemónicos y de estructuración simbólica que, aunque se constituyan a partir de prácticas occidentales, mantengan una impronta cultural en el fenómeno festivo, tal como ocurre con el Pawkar Raymi. Las identidades empiezan a estructurarse a partir de la realidad de la migración, y pueden ser tanto restringidas como liberadoras, pues "unen idiomas, tradiciones y lugares de manera coactiva y creativa, articulando patrias en combate, fuerzas de la memoria, estilos de transgresión, en ambigua relación con las estructuras nacionales y transnacionales" (Clifford, 1999, p. 21).

\section{El Pawkar Raymi en Santiago de Chile}

Desde hace 18 años, la celebración del Pawkar Raymi, en Chile, se realiza en la ciudad de Santiago, donde se concentra la mayor parte de los migrantes kichwa-otavalo. En los primeros años, el campeonato se limitó a pocas familias y amigos; a la fecha, en el día de la clausura puede llegar a congregar hasta mil personas. Esta festividad se ha institucionalizado y ha generado un espacio en el cual emergen una serie de sentidos particulares de la comunidad migrante, como los procesos de significación a partir de la memoria oral y el recuerdo, pues se carece de la configuración andina y la mítica cascada de Peguche. En este contexto la memoria, que es siempre constructiva, "se vuelve un elemento fundamental para el mantenimiento de un sentido de integridad" (Clifford, 1999, p. 62).

En Santiago, el Pawkar Raymi comparte una serie de significaciones identitarias con la ceremonia realizada en Peguche. La festividad tiene como evento principal el campeonato de fútbol, tal como se presentó desde sus inicios en Ecuador. No obstante, no se trata de un campeonato de fútbol tradicional mestizo, sino que se establece como una transgresión a la estructura del juego y al intento de establecer procesos de significaciones propias del ser indígena, relacionadas con el mestizaje, sin dejar de lado sus significaciones del nacimiento del Pawkar Raymi. 
La inauguración se realiza de manera solemne con el Himno Nacional del Ecuador, buscando reforzar el sentimiento de pertenencia a la nacionalidad ecuatoriana. Se hace alusión al significado del Pawkar Raymi y se reitera la importancia de mantener la tradición y no perder el sentido de pertenencia, muy arraigado en la comunidad otavalo. Quien anima el encuentro lo hace tanto en kichwa como en español. Camilo lo justifica "en razón principalmente de que los jóvenes ahora hablan puro español" (Camilo, 43 años). Esta acción, aunque no pretende educar a los jóvenes, busca establecer un vínculo con base en la lengua como símbolo de identidad y de pertenencia.

En Ecuador, a partir del año 2004 se cambia el concepto de Reina de Deportes por el de Nústa Pawkar Raymi. Esto implica para las madrinas y las candidatas a reina evidenciar sus conocimientos acerca del evento y otros aspectos culturales de su comunidad (Ordóńez, 2017). De igual modo que en Santiago, se concede mayor puntaje a las madrinas que conocen el significado del Pawkar Raymi, que estén usando la vestimenta típica y hablen en kichwa. Es un reconocimiento explícito a un proceso de trabajo personal de asimilación e incorporación de valores culturales que involucran tiempo y esfuerzo; de igual modo, se refleja en quienes poseen un fuerte capital cultural: familias, mujeres, quienes además son consideradas las guardianas y transmisoras de los saberes culturales.

El Pawkar Raymi es una celebración que requeriría, según algunos, un acto ritual, el Tumarina. Esta es la principal diferencia, en el contexto migratorio, entre Santiago y Ecuador: "Nada de rituales, no hacen nada, ni al empiezo no hacen rituales, solamente se organizan para qué hora le toca jugar" (Sergio, 35 años). Sobre todo, porque el espacio de la festividad no está configurado para el establecimiento y desarrollo de la simbología y cosmovisión con las que el hombre se relaciona con el mundo, pues en Ecuador esta festividad se estructura a partir de otras simbologías y significaciones, que prestan el contexto natural de la cascada, el río y las montańas permitiendo establecer una impronta única en el ritual: "Es un honor al florecimiento de la madre naturaleza, en especial de las chacras, a las que se preparan para la cosecha de los granos tiernos. El lavado de cara con flores tenía el significado de purificación de los líderes para que sean los mejores guías del pueblo" (Sarabino, 2007, p. 12).

La diferencia con Ecuador se hace también en referencia a la tradición de los medianos o castillos y al cucabi: "En Ecuador, [...] todas las personas que puedan llevan la comida para compartir y darle a la persona que está organizando y eso lo comparten con todos, y en cambio aqui [Chile] es difícil eso" (Sergio, 35 años). En rigor, esto responde a la idea del agradecimiento a la Pachamama, la Madre Tierra, y a los valores de solidaridad y de compartir en equidad. No obstante, las danzas a cargo de las mujeres, que ocasionalmente se han presentado en el Pawkar Raymi en la ciudad de Santiago, tienen un significado implícito de agradecimiento a la tierra. Pues si bien estas condiciones no se replican en Santiago, ello de ninguna manera excluye el ejercicio y fortalecimiento de la identidad indígena, ya que el acto festivo deriva en la comprensión de una cosmovisión comunitaria kichwa-otavalo y en una lucha contrahegemónica, que busca resignificar el sentido de ser indígena otavalo en el mundo mestizo chileno a partir de la experiencia diaspórica que muestra diversos grados de continuidad, diversos grados de 'algo parecido' a una memoria colectiva (Clifford, 1999, p. 21).

4 El cucabi es la porción personal de la comida comunal, que es una mezcla de alimentos, principalmente granos (mote, choclo, tostado, arroz, fréjol, habas, papas, queso, lentejas, melloco, carne), preparado por las mujeres y que se ofrece en todo tipo de evento; se coloca sobre un mantel en el suelo para ser repartido entre todos los presentes y degustado en una "pambamesa". 
Las nociones de capital cultural y capital social que plantea Bourdieu (1979) permiten una mejor comprensión del proceso por el cual se realiza la revalorización de los elementos culturales, que dotan a los agentes sociales de prestigio y poder en un campo social dado -en este caso, el espacio de la fiesta ritual del Pawkar Raymi-, en correspondencia con la posición que ocupan en la estructura social.

El capital cultural se manifiesta en tres formas: el capital cultural incorporado hace referencia a las disposiciones mentales y corporales; el capital cultural objetivado se presenta en forma de bienes culturales y, por último, el capital cultural institucionalizado, reconocido por las instituciones políticas, por ejemplo, los títulos académicos (Bourdieu, 1979). Por su parte, el capital social tiene que ver con la posesión de una red duradera de relaciones, de conocimiento y reconocimientos mutuos, que marcan la pertenencia del agente a un grupo social determinado (Bourdieu, 1980).

Los saberes culturales acerca de la fiesta ritual, así como el uso de la vestimenta y la lengua son resignificados, en tanto son revalorizados en su condición de capital social y cultural. Estos elementos, como bienes culturales objetivados, han sido apropiados desde el valor otorgado, de manera individual, por el capital cultural incorporado, el cual transforma el tener en ser, es decir, una posesión hecha cuerpo "que se ha convertido en parte integrante de la persona, en habitus" (Bourdieu, 2001b, p. 140). Aspectos que se manifiestan en las formas de andar, de hablar, de vestir, de comportarse; pues la noción de habitus se refiere al conjunto de formas de obrar, pensar y sentir relacionadas con ciertas condiciones de existencia (Bourdieu, 1979); constituyéndose en la materialización de la memoria colectiva que se va configurando en espacios estructurados y estructurantes que se transmiten de generación en generación, modelando la vida actual de los individuos. Sobre todo, posibilita orientarse a sus propios espacios societales y diferenciarse de otros, guardando las raíces, pero especialmente permitiendo recrear las acciones del pasado al presente (Guerrero, 2002).

Mantener la tradición y la cultura es la consigna generalizada en el Pawkar Raymi. En este sentido el discurso inaugural cumple una función pedagógica: "Para no perder la costumbre, para reunirnos todos los ecuatorianos, para disfrutar, para participar un rato entre todos, para compartir" (Camilo, 43 años); configurándose algo así como un espacio para recordar y retornar simbólicamente desde la diáspora a la tierra ecuatoriana. Y cumpliendo una función integradora desde el sentido de Estado-nación, en la que se reafirma la identidad en tierra extrańa, compartiendo espacios simbólicos que rompen con la cotidianidad del comercio. Es decir, volver al espacio de encuentro en la comunidad, lejos de ella, pero con aquellos que pertenecieron a esa tierra, con aquellos que se encuentran en una situación determinada por el fenómeno de la migración:

En la medida que generaciones futuras, forzadas o desplazadas a pueblos o ciudades, no tienen ninguna intención realista de vivir de manera permanente en sus lugares tradicionales, la conexión a las tierras natales perdidas se aproxima a una relación diaspórica, con su característica forma de nostalgia, nacionalismo de larga distancia y performances desplazados de su "herencia cultural" (Clifford, 2010, p. 226).

En el Pawkar Raymi se exalta tanto la nacionalidad como la etnicidad: "Nosotros somos de Otavalo y solo los ecuatorianos de Otavalo, solo entre ellos no más hacemos acá la fiesta" (Jacinto, 22 años). Ser indígena es condición necesaria para participar en el campeonato, condición que afirma y marca las fronteras étnicas. Es decir, "aquellos actos que los individuos realizan 
en el plano de las distinciones sociales, especialmente las de inclusión y exclusión" (Carter y Fenton, 2010, p. 5). Esto produce una vivencia espiritual y personal en medio del grupo que busca crear o establecer un principio de conexión en este punto, no solo con la tierra sino con la comunidad que se encuentra lejos. De este modo, las fronteras étnicas canalizan la vida social estableciendo una organización compleja de relaciones y de conductas para los miembros del grupo, siendo la lengua un elemento diferencial ineludible, así como otros elementos identitarios:

Puede entrar alguien a jugar, mestizo, digamos, pero después si o si cualquier equipo ya dice: él no es ecuatoriano. Aunque juegue mal o aunque juegue bien, él no es indigena. Y uno va a preguntarle jeres indigena? y trata de mentir, decir: "SSi, soy indigena!". Ahi es donde uno entra a decirle: entonces, háblame en el idioma que es de nosotros y nosotros le preguntamos en kichwa y tiene que responderle en kichwa $y$ si no es, ya el equipo queda sin puntos (Darwin, 18 años).

Si bien la lengua es un marcador significativo de la identidad comunitaria, al mismo tiempo su uso se ha ido perdiendo, pues la mayoría de los jóvenes entienden el kichwa, pero no lo hablan. Sin embargo, ello no implica una contradicción, sino más bien un espacio de reivindicación de la identidad en la que los principios simbólicos pasan a constituirse en procesos de acceso a una fiesta y al hecho lúdico en el espacio temporal y físico; pero también establece nuevas formas de relación con la comunidad, a pesar del intercambio simbólico que representa conocer esa lengua, pues esta aumenta así su valor simbólico y su prestigio sobre su valor comunicativo.

El vestido o el idioma entre los blancos mestizos no son rasgos diacríticos exclusivos de su identidad, pero entre algunos de los pueblos indios, el vestido o el idioma continúan siendo un rasgo diacrítico identitario muy importante, que hace evidente su pertenencia y diferencia (Guerrero, 2002, p. 104).

Los ámbitos de uso de la lengua tienen relación con la protección de los símbolos y costumbres propias de una cultura, y se encuentran en el espacio interior o endógeno de la misma (la familia, lo sagrado, las expresiones culturales simbólicas y religiosas, cosmovisión, etc.); son la base para el mantenimiento de las especificidades culturales, de manera que puedan ser reivindicadas frente a aquellos a los que se considera los otros (Inuca, 2017). Y aunque la lengua materna puede ser negada, "se sabe bien que muchas personas que tienen por lengua materna un idioma indígena, lo ocultan y niegan que lo hablen” (Bonfil Batalla, 1987, p. 28), también se constituye en un proceso de reafirmación de la identidad y el sentido de pertenencia a la comunidad.

La relación entre fiesta y cultura es un punto medular en esta investigación. En la celebración del Pawkar Raymi se establecen principios de identidad, pertenencia, simbolismo, lucha, estrategia política, entre otros, constituyendo una relación clara entre la fiesta y el ser indígena kichwa-otavalo: "Una de las funciones de todo ritual festivo más significativa y unánimemente reconocida es la de expresar simbólicamente el desiderátum de integración e identidad colectiva de la comunidad que lo celebra" (Homobono, 1990, p. 45). De ahí que las familias y la comunidad otavalo se apropien de un espacio en la ciudad de Santiago de Chile, como un punto de encuentro.

En Santiago, la fiesta se establece en el lugar que se les permite, en un acuerdo tácito entre la ciudad y la comunidad migrante. En ese espacio y en ese momento se reproducen contenidos 
comunitarios y culturales que se constituyen en la impronta de la cultura: "Como somos entre runas, entre indigenas, ya es si o sí, uno tiene que cumplirlo y asi es" (Charly, 19 años). Este testimonio expresa la concepción del encuentro como un compromiso ineludible, para mantener la tradición, que estaría ligada a la usanza indígena de "pasar el cargo", cuya finalidad es la de perpetuar las fiestas por medio de los "padrinos", aunque, en estricto rigor, en el Pawkar Raymi no existen los "priostes", sino un comité organizador que administra y agencia recursos, principalmente a través de las redes de parentesco o de afinidad, no solo local sino transnacional (Ordóńez, 2008). En Santiago, desde el año 2014, la organización de la fiesta está a cargo del equipo vicecampeón.

El Pawkar Raymi se financia mediante el cobro de diferentes servicios, el principal de ellos es la inscripción de los equipos de fútbol participantes, a razón de 580 dólares por cada uno; valor directamente relacionado con la cuantía del premio: "Mientras más vale la inscripción más [alto] tiene que ser el premio, eso es sí o sí" (Darwin, 18 años), por lo que se constituye en un elemento motivador en la competencia. Los organizadores del evento deben cubrir los anticipos de los gastos que, junto con los premios para los finalistas, pueden llegar a 25000 dólares americanos. Asistir al Pawkar Raymi en Santiago implica gastos onerosos: "Todo es plata allá y sí, se gasta una buena cantidad para estar ahi [...] todo por el deporte" [risas] (Ángel, 33 años). Algunos asisten solamente a la final del campeonato: "Siempre vamos a las finales nomás porque es mucho gasto y no tenemos nosotros dónde llegar” (María, 45 años).

El gasto puede quedar en segundo plano por el acto festivo en sí mismo, que a su vez tiene un fuerte anclaje en el sentido de pertenencia identitaria del indígena, quien regresa a un espacio, un punto de encuentro, para establecer lazos con la comunidad de origen, en el encuentro con los otros, donde el capital social se constituye a partir de los recursos que se generan por la pertenencia a un grupo. Esto es "[...] la totalidad de los recursos potenciales o actuales asociados a la posesión de una red duradera de relaciones más o menos institucionalizadas de conocimiento y reconocimiento mutuos" (Bourdieu, 2000, p. 148). Al punto de establecer un principio de igualdad identitaria y espiritualidad como fundamento de la fiesta misma.

Una característica de los kichwa-otavalo en Chile es su facilidad para adaptarse y su sentido del ahorro; la gran mayoría abarata costos con el ahorro del hospedaje, pues pernocta en carpas o en el interior de sus minivanes ya que llevan muchos productos. De modo que ahorro y derroche es la paradoja para instaurar una relación social con la lógica no solo de la fiesta y su simbolismo, sino también dar paso a la acción racional, al principio de la economía, lo que conlleva a su uso en el análisis del propio sistema social, estableciendo modelos de relación tanto económicos como sociales que conlleven a procesos de intercambio simbólico y económico (Coleman, 2000).

Para algunos, hay intereses económicos en la organización del evento: "ahora se lo mira ya con un sentido de lucro, de dejar ganancia a los organizadores [...] la mayoría ya lo está viendo en ese aspecto" (Sergio, 35 años). Esta creencia de Sergio coincide con el análisis de Sarabino en Ecuador: "Se podría decir que el Pawkar Raymi se ha convertido en espacios de comercio, perdiendo la esencia misma de la tradición que representa esta fiesta” (Sarabino, 2007, p. 42). Esta situación se entendería desde el capital social y el espacio de representación de la riqueza de los miembros de la comunidad, quienes aprovechan dicho contexto para establecer relaciones de diversos tipos. 
En la fiesta del Pawkar Raymi no solo se establecen relaciones en torno a la capacidad de negociación e intercambio de mercancías, sino que se da paso a una comprensión de la dicotomía masculina y femenina. En este caso, en Peguche, el fútbol como un evento masculino y global y el Tumarina, a su vez, como el ritual femenino del agua y las flores. Por su parte en Chile, el parangón con el Tumarina, en el sentido de un acontecimiento que alude a lo femenino, se podría establecer con la danza, la moda y en la preparación de la comida a cargo exclusivo de las mujeres. Así, como otro atractivo de la fiesta se presenta la venta de ropa típica, casi con exclusividad ropa femenina como blusas, hualcas, alpargatas y otras prendas.

Este evento también convoca lo doméstico, lo femenino y a las mujeres en el rol asignado por el grupo, evidenciándose esta como generadora de recursos económicos. "Yo vine acá para trabajar", dice Adriana, quien participó en la festividad del Pawkar Raymi con un puesto de comida típica. También se hace hincapié en el mantenimiento de las costumbres: "Yo participo con la gastronomía, y ellos [la comunidad otavalo] ahi se divierten y van, compran. Por ejemplo, cada uno preparamos de distintas formas, entonces ahi compran, comen, y les gusta [...] y siempre, por decir, las costumbres nosotros no perdemos" (Adriana, 37 años), estableciendo claras representaciones sobre lo que debe hacer cada uno de los miembros de la comunidad:

La representación que elabora un grupo sobre lo que debe llevar a cabo define los objetivos y procedimientos específicos para sus miembros. Aquí descubrimos una primera forma de representación social: la elaboración por parte de una colectividad, bajo inducción social, de una concepción de la tarea que no toma en consideración la realidad de su estructura funcional (Moscovici, 2008, p. 470).

El Pawkar Raymi tiene un gran poder de convocatoria en la comunidad otavalo en Chile, congregada alrededor del campeonato de fútbol, sobre todo por una necesidad de los miembros de la comunidad kichwa-otavalo de reivindicar un espacio cultural y su sentido de pertenencia, rompiendo con la cotidianidad de migrante, estableciendo espacios de interacción simbólica y abriendo una instancia lúdica y festiva que une, pero a la vez permite establecer relaciones comerciales, afectivas y comunitarias en el encuentro con los otros. Se adapta la fiesta a un contexto diferente al de Agato o Peguche, pero desde la realidad de migrante se reescribe la tradición primera para fundamentar el encuentro con la tierra y establecer una memoria comunitaria.

\section{Pawkar Raymi: punto de encuentro, un espacio para vivir la cultura}

El Pawkar Raymi en Chile se constituye en un momento de encuentro de los migrantes kichwa-otavalo con el objetivo de compartir. En este sentido se revela como una reunión interétnica alrededor del campeonato de fútbol como elemento fundamental; es un espacio para vivir la cultura, para el encuentro familiar, para socializar y hacer amigos, para la diversión, el cotilleo y la moda: "Es un ambiente más familiar porque van varios runas y se pasa bien con los amigos, más por el fútbol que nos gusta harto" (Charly, 19 ańos).

La psicología social y ambiental estudia los vínculos entre las personas y los espacios, entendidos como una construcción social, esto es, la territorialidad, el espacio simbólico, la identidad. Se entiende así que dicho espacio -en este caso un estadio en un barrio de Maipú e independientemente de la propiedad legal- cobra una significación particular al constituirse, al igual que una 
embajada, en un trozo de Ecuador, un territorio primario percibido como un espacio propio y familiar; la patria y la casa misma que posibilitan la expresión de la identidad y los valores.

Esto tiene lugar por dos vías: la acción-transformación y la identificación simbólica. La primera está relacionada con la territorialidad y el espacio personal y la segunda, con procesos afectivos, cognitivos e interactivos. La identificación simbólica posibilita que las personas y el grupo se reconozcan en el entorno y se autoatribuyan las cualidades de ese entorno como determinantes de su identidad. Así, al transformar el espacio, las personas dejan huella, marcas cargadas simbólicamente, dándole un significado individual y social a través de los procesos de interacción (Vidal i Moranta y Pol, 2005):

Es como aqui. Como con los chilenos no se lleva uno bien, también, todos los días no se puede llevarse bien, en cambio entre nosotros entre indigenas hablamos en confian$z a$, jugamos o hacemos bromas, todo eso, y estar ahi [en el estadio, en el lugar donde se realiza el Pawkar Raymi] es como estar en Ecuador, y en cambio cuando salimos de allá ya es como que otra vez al trabajo (Darwin, 18 años).

El acto festivo, en el espacio apropiado simbólicamente, va a ser adaptado a la realidad de Santiago, pero estableciendo un proceso de autodefinición y pertenencia que responde a la necesidad de establecer procesos de encuentro que, por no poder retornar a Otavalo a celebrar la fiesta, genera el espacio necesario para "condensar varios niveles de lucha simbólica y reorientación comunitaria. Es un proceso que sintoniza en un mismo nivel la búsqueda de afirmación identitaria" (Ordóńez, 2008, p. 70), pero acoplándose a la realidad que desde la migración deciden vivir, en la que la camaradería y el compañerismo se potencian por compartir una misma realidad:

No se extrañaba nada más, veías a la gente indígena compartiendo, estabas en la casa mismo. De hecho, en esos momentos uno se siente como en casa, se siente que ya tienes derecho para todo, lo que quieras hablar, decir, reir; cosa que en lugares de trabajo no es lo mismo, estar rodeado de gente chilena. A veces estás comiendo algo y te ven como raro: “QQue está comiendo?". Entonces, dentro del Pawkar Raymi, eso es lo que nos liberamos totalmente dentro del estadio y aprovechamos, comemos, disfrutamos, reimos, incluso hablan las groserias que se dicen en Ecuador, como en el idioma de Ecuador y eso (Ángel, 33 años).

El Pawkar Raymi, al igual que en Ecuador, es un espacio para el reencuentro familiar. A él se convocan los parientes que llegan de diferentes partes de Chile e incluso de otros países. También es la oportunidad para enseńar y continuar las tradiciones, proceso de reivindicación y educación intergeneracional a los hijos de los migrantes que, aunque no conozcan Otavalo, logran incorporar una identidad y pertenencia étnica. Los niños, desde los más pequeños, juegan, comparten y se animan al ver a sus padres o hermanos interactuar en la cancha y fantasean de participar un día en algún equipo:

Ya crecen con esa idea de [que] cuando sea grande voy a jugar en ese equipo [...] he visto de la misma hinchada que vienen a decir: "Hazme jugar el próximo año", niños que hace cinco años vi que gritaban por un gol, ahora ellos participan y ven que es bueno y les gusta y creo que de esa manera vamos también sembrando nuestro pequeño granito a la cultura (Ángel, 33 años). 
En el Pawkar Raymi 2005 en Ecuador, en el evento del Runa Kay se introdujo la ceremonia de la "transmisión de la herencia cultural" entre padres e hijos (Ordóńez, 2017, p. 273), con la que se intenta asegurar la revalorización y preservación de las tradiciones y un legado cultural a las futuras generaciones. En Chile, la comunidad otavalo ha mantenido y fomentado ciertas tradiciones y festividades rituales tales como el Inti Raymi y el Pawkar Raymi que, de diversas maneras, les ha permitido generar espacios de empoderamiento al interior de la comunidad indígena y en el espacio interétnico en donde "el nuevo sujeto es definido por un anclaje territorial 'ancestral' delimitado y por derechos colectivos, culturales y políticos que lo ligan al territorio, y que se pone de manifiesto en las denominaciones legales de los grupos" (Losonczy, 2007, p. 272).

El Pawkar Raymi es una oportunidad para vivir la cultura en un espacio claramente marcado por las fronteras étnicas que persisten a pesar de la movilidad de sus miembros. En él se manifiestan los valores de la cultura kichwa-otavalo.

Quizás todos tenemos en común el trabajo, conversamos del trabajo: “Cómo te va en el trabajo?". Y generalmente nuestras conversaciones son: “Cómo te está yendo? ¿Cómo te fue en otro país? ¿Cómo está tu vecino? Él estaba en el otro país, ¿cómo le fue?". Conversaciones asi surgen y, el Pawkar Raymi es para eso, para encontrarse, conversar; quizá no sea la finalidad, pero eso es lo que se hace [...]. Es una tradición buena y ha unido a los otavaleños fuera del país, es una tradición bonita que se ha mantenido estando fuera del país [...]. La idea es esa también, yo creo, de fomentar, de seguir con nuestra cultura, más estando lejos del país, tratando de ser algo (Ángel, 33 años).

El Pawkar Raymi cumple una función integradora, en el encuentro se genera un sentimiento de pertenencia, "para no olvidar nuestras raices, de dónde vinimos, que de eso estamos hechos", dice Juan (42 años). De igual modo, su hijo Darwin hace referencia a la importancia que tiene para él la celebración del Pawkar Raymi como el camino para mantener las costumbres y tradiciones: "Todo eso como el pelo largo y la vestimenta de Ecuador me gustaría que no se pierda [...] y no olvidar nunca de dónde vinimos, porque asi lo veo yo, es algo valioso que tengo y no lo quiero perder" (Darwin, 18 años). Estos sentidos de pertenencia ignoran y sobrepasan las fronteras de la nación, constituyéndose en una vía para la reafirmación de la identidad étnica; de este modo, la tradición es generadora de identidad. A su vez, la identidad cultural es una construcción social e histórica, en continua transformación, cuyo sentido es posibilitar el autorreconocimiento (Vergara Estévez y Vergara D., 2002).

Por su parte, Anderson considera que a los jóvenes no les interesan mucho las tradiciones, por lo tanto, ya sea en Santiago o en Ecuador, al Pawkar Raymi asisten solo por el deporte y diversión:

La juventud acá si se van [a Ecuador] para Carnaval y ellos van como para jugar carnaval con agua, no para practicar esas tradiciones de Pawkar Raymi ni nada. La juventud va por diversión, es para ellos como descansar un rato. Obviamente son partícipes, ellos serían los que se motivarían para cuidar esa tradición, pero dudo, porque no están viviendo en Ecuador. Todos los que van a disfrutar viven afuera, también en cada país donde están radicados quieren hacer lo mismo, pero nunca va a ser lo mismo, solo recuerdan nomás y así, poco a poco se va perdiendo (Anderson, 30 años). 
La categoría juventud en el mundo kichwa-otavalo, en el contexto de la migración, es fundamental para comprender la dimensión didáctica y educativa del festejo, ya que muchos de los jóvenes no conocen personalmente el Ecuador. Por ello, en el encuentro con los otros miembros migrantes de la comunidad recrean su identidad como jóvenes kichwa que se relacionan con sus pares chilenos. Es un espacio de encuentro de la juventud con las generaciones precedentes, estableciéndose un modelo de endoculturación: "una experiencia de aprendizaje parcialmente consciente y parcialmente inconsciente a través de la cual la generación de más edad incita, induce y obliga a la generación más joven a adoptar los modos de pensar y comportarse tradicionales" (Harris, 2004, p. 4), que en el caso del Pawkar Raymi celebrado en Chile, logra acercar al joven a la cosmovisión kichwa durante los momentos en los que este se relaciona con sus iguales.

Vivir en condición de migrante limita la manifestación y reproducción de la cultura. No obstante, los indígenas otavalo mantienen sus festividades importantes:

\section{En todo el mundo mismo, no perdemos esa costumbre. En todas partes, si usted entra a internet y ve indígenas ecuatorianos en Bélgica, en China, en Corea, ellos ahi siem- pre están con las costumbres [...]. Entonces, en ese sentido, siempre hay la costumbre, no se pierde. Eso, los niños igual van viendo eso y no pierden la cultura, van hacién- dole crecer más (Adriana, 37 años).}

El Pawkar Raymi es también una expresión de una cultura autónoma en el contexto de una sociedad diversa que acoge a los migrantes. Los kichwa-otavalo, en condición de grupo indígena migrante, mantienen el control cultural, es decir, la capacidad social de decisión sobre los elementos culturales propios, los cuales se modifican, restringen, amplían y transforman incesantemente, siendo está la base mínima de la cultura autónoma, indispensable para el mantenimiento de la identidad colectiva como grupo étnico diferenciado (Bonfil Batalla, 1991).

Por otro lado, en el Pawkar Raymi se genera un espacio social caracterizado por la demostración de poder y riqueza en los momentos de convivencia con los demás otavalos: "El dinero es un sinónimo de prestigio en la medida que se logra acumular, es decir, alcanzar un nuevo estatus dentro de la dinámica propia de los kichwa-otavalo" (Sarabino, 2007, p. 23). El acto de mostrar el poder político y adquisitivo en la comunidad establece una comprensión de capital social, pero a la vez de jerarquía dentro de la comunidad, donde los organizadores adquieren un rol fundamental al presentarse como miembros activos pero también como aquellos que mantienen la cultura en el contexto de la migración.

Esta situación se puede abordar desde el concepto de capital social de Bourdieu, entendido como las "diferencias residuales ligadas, grosso modo, a los recursos que pueden reunirse, por procuración, a través de las redes de 'relaciones' más o menos numerosas y ricas" (Bourdieu, 2001a, p. 16), y configurando un proceso de relación simbólica no solo en la exhibición de las capacidades adquisitivas de las respectivas familias, sino también en los espacios de encuentro y establecimiento de relaciones comerciales. A su vez, la relación simbólica se realiza a partir del capital simbólico, que es "la forma que toman los distintos tipos de capital en tanto que percibidos y reconocidos como legítimos" (Bourdieu, 1994, p. 3).

Estas diferencias sociales se manifiestan en la manera de vivir el Pawkar Raymi, esto es, según el orden de las estructuras sociales, se ocupa un lugar en el campo social. No obstante, durante 
la fiesta, los rituales liminales posibilitan, temporalmente, la inversión del estatus social (Ordóńez, 2017). Así, la sociedad diferenciada en un sistema jerárquico se torna en una comunidad indiferenciada, una antiestructura, la communitas que, en el espacio de lo liminal, "marca un momento en y fuera del tiempo, dentro y fuera de la estructura social secular" (Turner, 1988, citado en Cruz, 2017, p. 357). Es decir, la estructura social jerárquica en un momento coyuntural puede trastocarse y dar paso a un conglomerado liminal, un actor colectivo, que interinamente cambie la estructura para reorganizarse después. Así, la communitas se afirma simbólicamente por medio de rituales como los ligados al ciclo agrícola en los que se invierten los roles sociales (Cruz, 2017).

En el Pawkar Raymi en Santiago de Chile, se puede observar una clara ostentación del éxito económico entre algunos, en la posesión de buenos vehículos y ropa de moda, condición que, en la liminidad ritual, no se opone a la proliferación y prevalencia de los sentimientos que surgen en la communitas espontánea de la reciprocidad inmediata como una experiencia única, efímera, caracterizada, según Turner (1988, citado en Cruz, 2017), por una estructura de relaciones libres entre los individuos.

\section{Nuevos significados}

El Pawkar Raymi surgió y se sostiene como un intento por revalorizar las expresiones culturales, vivenciando colectivamente prácticas tradicionales y valores culturales de las comunidades originarias que se estaban perdiendo. Esta manifestación, a su vez, trasciende la realidad local de Agato y Peguche, estableciendo una vinculación del mundo indígena y migración. En donde, el principio fundamental del retorno se constituye en un punto de quiebre entre la comunidad que acoge, pero en este punto, son comunidades que se reúnen en el contexto de la migración, como fundamento clave de la presencia en una comunidad diferente a la que nació la tradición, estableciendo un proceso de pertenencia afectiva, espiritual y simbólica en condiciones adversas a la comunidad de origen.

En la condición de migrantes y con el paso del tiempo los significados del Pawkar Raymi se transforman; para los jóvenes, la ritualidad del florecimiento y el agradecimiento a la Pachamama son desconocidos. Aun así, el rito remite a un pasado nostálgico de la vida en la comunidad y se establecen puntos de encuentro para la revitalización simbólica del ser kichwa-otavalo, como fundamento ontológico de la pertenencia. Mas, todos saben que para asistir a esta festividad los migrantes otavalo regresan a Ecuador y consideran que, quienes no han podido hacerlo, la replican exactamente igual en el país de residencia. Por lo tanto, pese a la imposibilidad del viaje, se conserva el significado de la fiesta del retorno. En este caso no desde el objetivo de regresar a las comunidades de Agato o Peguche, sino que las nuevas generaciones se mantengan enlazadas por medio de la performance reeditada en la ciudad de Santiago.

La venta de ropa indígena y comida típica en el Pawkar Raymi es otro intercambio simbólico que enlaza la migración con la tierra de origen, haciendo perdurar con ello la importancia de la tradición y el vestido, al constituirse ambos en formas de representación y autorrepresentación de la identidad en el contexto de la migración. Especialmente es el mundo de la mujer -con sus labores domésticas y de cuidado-, el que tiene a su cargo la preservación de la cultura. "[E]s precisamente ella la encargada de mantener y reproducir la identidad cultural del grupo, lo que se expresa sobre todo en la vestimenta tradicional y en los adornos corporales que únicamente ellas mantienen” (Ruiz Balzola, 2008, p. 55). 
La celebración del Inti Raymi y el Pawkar Raymi son las dos fiestas de mayor convocatoria para los kichwa-otavalo en Chile; sin embargo, el Pawkar Raymi es la única fiesta que convoca multitudinariamente al encuentro étnico. La celebración del Inti Raymi es localizada y, en el contexto de la migración en Chile, se limita a un solo día; no obstante, conserva su ritualidad: se realiza la entrega a los organizadores de castillos (fuegos artificiales), se disfrazan de diferentes personajes, tocan su música, zapatean y, además, al compartir el cucabi refuerzan los lazos comunitarios de amistad y reciprocidad. Por su parte, el Pawkar Raymi es un motivo de encuentro que permite la revitalización de la identidad individual reforzada en la identidad colectiva, de un 'nosotros' que le da el sentido de identidad en el contexto migratorio que busca afianzar el principio de pertenencia.

Los kichwa-otavalo no han podido conservar todas sus costumbres y creencias totalmente autónomas; algunas de ellas se mantienen, otras han desaparecido, pero principalmente, se resignifican y se establecen otras relaciones simbólicas en las nuevas interacciones. Particularmente en el contexto de la migración, en la celebración del Pawkar Raymi en Santiago de Chile, se manifiesta principalmente el sentido de pertenencia al endogrupo y un cierto nacionalismo; pues ellos se presentan ante los chilenos, y a la vez son reconocidos por estos, como ecuatorianos, aun cuando algunos de ellos son nacidos en Chile.

Finalmente, la celebración del Pawkar Raymi, como una invención de la tradición, estaría direccionada al fortalecimiento de una identidad étnica transnacional, tangencial al Estadonación, que se reafirma como una extensión de la comunidad en el contexto de la ciudad de Santiago de Chile, en donde se juegan roles fundamentales como el simbolismo, pertenencia, identidad, tradición, cultura, que permite tejer variadas posibilidades al migrante para reafirmar su "ser" kichwa-otavalo "siendo" migrante. En este sentido, permite generar puntos de encuentro para establecer procesos de retorno a su comunidad e identidad, pero permaneciendo en las ciudades y países que los acogen.

\section{Referencias citadas}

Aravena, A. y Baeza, M. (2013). Violencia Simbólica en el Chile contemporáneo. Estrategias de respuesta en relaciones de alteridad. Revista Internacional de Sociología, 71(3), 543-565.

Aravena, A. y Silva, F. (2009). Imaginarios sociales dominantes de la alteridad en la configuración de los límites etnonacionales de la identidad chilena. Sociedad Hoy, 17, 39-49.

Bonfil Batalla, G. (1987). México profundo. Una civilización negada. Ciudad de México: Titivillus.

Bonfil Batalla, G. (1991). La teoría del control cultural en el estudio de procesos étnicos. Estudios sobre las Culturas Contemporáneas, IV(12), 165-204.

Bourdieu, P. (1979) "Los Tres Estados del Capital Cultural”. Sociológica, 5, 11-17. UAM- Azcapotzalco, México. Recuperado de http://cort.as/-M102

Bourdieu, P. (1980). El capital social. Apuntes provisionales. Zona abierta, 94-95, 83-87.

Bourdieu, P. (1994). ¿Qué es lo que hace a una clase social? Acerca de la existencia teórica y práctica de los grupos. Journal of Sociology, 7-21. Berkeley, CA.

Bourdieu, P. (2000). Cuestiones de Sociología. Madrid: Itsmo. 
Bourdieu, P. (2001a). Las estructuras sociales de la economía. Buenos Aires: Manantial.

Bourdieu, P. (2001b). Poder, derecho y clases sociales. (2ª ed.). Bilbao: Desclée de Brouwer.

Carter, B. y Fenton, S. (2010). Not Thinking Ethnicity: A Critique of the Ethnicity Paradigm in an Over-Ethnicised Sociology. Journal for the Theory of Social Behaviour, 40(1), 18.

Clifford, J. (1999). Itinerarios Trasculturales. Barcelona: Gedisa.

Clifford, J. (2010). Diversidad de experiencias indígenas: diásporas, tierras natales y soberanías. En De la Cadena, M. y Starn, O. (Eds.). Indigeneidades contemporáneas: cultura, politica y globalización (pp. 221249). Lima: IEP - IFEA.

Coleman, J. (2000). Social capital in the creation of human capital. En Lesser, E. Knowledge and social capital (pp. 95-120). Boston, MA: Butterworth Heineman.

Comas d'Argemir, D. y Pujadas Muńoz, J. (1991). Familias migrantes: reproducción de la identidad y del sentimiento de pertenencia. Papers. Revista de Sociologia, 36(0), 33-56. https://doi.org/10.5565/rev/papers/ v36n0.1586

Cruz, J. de J. (2017). El concepto de experiencia en Víctor W. Turner, E. P. Thompson y Anthony Giddens: Un diálogo entre antropología social, historia y sociología. Sociología Histórica, 7, 345-375.

Díaz Polanco, H. (2009). Diez tesis sobre identidad, diversidad y globalización . Quito: Centro de Investigaciones y Estudios Superiores en Antropología Social.

Escobar, T. (2009). Nuevas aproximaciones a la teoría de la fiesta. En Pereira, J. La fiesta popular tradicional en el Ecuador (pp. 11-23). Quito: Ministerio de Cultura Ecuador.

Escudero, C. (2017). Las fiestas populares en el Ecuador: Un factor de interacción comunitaria. Universidad y Sociedad, 9(2), 27-33.

Estrada Nasder, B. (2007). Recrear la espiritualidad ancestral a través de la danza y la música como formas de educación propia. Revista Educación y Pedagogía, XIX(49), 100-102.

Guerrero, P. (2002). La cultura. Estrategias conceptuales para entender la identidad, la diversidad, la alteridad y la diferencia. Quito: Abya-Yala.

Harris, M. (2004). Antropología Cultural. Madrid: Alianza.

Hobsbawm, E. J. y Ranger, T. (2002). La invención de la tradición. Barcelona: Editorial Crítica.

Homobono, J. I. (1990). Fiesta, tradición e identidad local. Cuadernos de etnología y etnografía de Navarra, 22(55), 43-58.

Inuca, J. (2017). Yachay tinkuy o encuentro y confrontación de saberes: genealogía de la interculturalidad y del buen vivir en la educación de los pueblos kichwas del Ecuador desde mediados del siglo XX. Tesis de doctorado. Recuperado de: http://repositorio.flacsoandes.edu.ec/handle/10469/12808

Jensen, M. (2009). Inmigrantes en Chile: la exclusión vista desde la política migratoria chilena. En Serie Investigaciones. Vol. 7. Temáticas migratorias actuales en América Latina: remesas, politicas y emigración (pp. 105-130). Río de Janeiro: ALAP. 
Larraín, J. (2003). El concepto de identidad. Revista Famecos, 10(21), 30-42.

Losonczy, A.-M. (2007). El criollo y el mestizo. Del sustantivo al adjetivo: categorías de apariencia y de pertenencia en la Colombia de ayer y de hoy. En De la Cadena, M. Formación de la indianidad (pp. 261277). Bogotá: Envión.

Martínez, P. J. (2003). El encanto de los datos. Sociodemografía de la inmigración en Chile según el censo del 2002. Serie Población y Desarrollo, 49. Cepal.

Moscovici, S. (2008). Psicología Social II. Madrid: Paidós.

Ordóñez, A. (2008). Migración transnacional de los Kichwa Otavalo y la fiesta de Pawkar Raymi. En Torres, A. y Carrasco, J. (Eds.). Al filo de la identidad: la migración indígena en América Latina (pp. 69-89). Quito: FLACSO / LACSO.

Ordóñez, A. (2017). La migración transnacional en Peguche, Ecuador, y la fiesta del Pawkar Raymi. Quito: UASB.

Ruiz Balzola, A. (2008). Estrategias, inversiones e interacciones de las mujeres migrantes kichwa otavalo. En En Torres, A. y Carrasco, J. (Ed.). Al filo de la identidad: la migración indígena en América Latina (pp. 47-65). Quito: FLACSO.

Sarabino, Z. (2007). El proceso de constitución de las élites indigenas en la ciudad de Otavalo (FLACSO sede Ecuador). Recuperado de: http://repositorio.flacsoandes.edu.ec/handle/10469/100

Torres, A. (2005). De Punyaro a Sabadell... la emigración de los kichwa otavalo a Cataluña. En Herrera, G., Carrillo, M. y Torres, A. (Eds.). La migración ecuatoriana: transnacionalismo, redes e identidades. Quito: FLACSO.

Tuaza, L. A. (2017). La fiesta del Inti Raymi en la construcción del Estado plurinacional en el Ecuador. Amérique Latine. Histoire et Mémoire. Les Cahiers ALHIM [En línea]. http://journals.openedition.org/ alhim/5703.

Vergara Estévez, J. y Vergara D. J. (2002). Cuatro tesis sobre la identidad cultural latinoamericana, una reflexión sociológica. Revista de Ciencias Sociales (Cl), 12, 77-92.

Vidal Moranta, T. y Pol Urrútia, E. (2005). La apropiación del espacio: una propuesta teórica para comprender la vinculación entre las personas y los lugares. Anuario de Psicología, 36(3), 281-297.

Yapud, G. (2015). Pawkar Raymi: tensiones y confrontaciones de clase, edad e identidad a partir de la migración transnacional en las comunidades de Agato y Peguche. Tesis de especialización. Recuperado de: http://cort. as/-M12A. 